\title{
The Langeland AED project - call for shorter response times (FirstAED)
}

\author{
Finn Lund Henriksen ${ }^{1 *}$, Henrik Schakow², Axel Brandes ${ }^{1}$, Bo Kaewkongnok ${ }^{1}$, Mogens Lytken Larsen ${ }^{1}$ \\ From 4th Danish Emergency Medicine Conference \\ Roskilde, Denmark. 25-26 November 2011
}

\section{Background}

The island of Langeland is a part of peripheral Denmark characterized by long ambulance response times and long distances to the nearest hospitals. Cardiopulmonary resuscitation (cpr) is provided by 200 trained lay rescuers. The population has purchased 85 automated external defibrillators (AEDs) which are available around the clock and placed less than two kilometres apart.

Most of the cardiac arrests occur at home and the rescuers are called by their private telephone. The full potential of the Langeland AEDs has not yet been achieved because of too long rescuer response times.

The project is a collaboration between the AED Centre Odense University Hospital, the Region of Southern Denmark, the Langeland AED project and the company FirstAED.

\section{Methods}

Over the next 24 months every rescuer will use an iPhone $4 \mathrm{~S}$ as a rescuer telephone. The IT-system (FirstAED), based on GPS technology, will immediately find the geographically closest rescuers. The system is not dependent on the rescuers' residence. At first, the ten closest rescuers are alarmed; if, and as soon as, they do not respond, the next closest batch of ten are alarmed. Three responders participate: Rescuer 1 and 3 hurry to the cardiac arrest and rescuer 2 collects the AED. The FirstAED technology will open all the locked AED cabinets within a radius of one kilometre. During the resuscitation process and before the arrival of the ambulance, the rescuers will receive advice and feedback from the central ambulance service (AMK).

\section{Results}

Over the last two years, the AEDs have been used 7 times at cardiac arrests on Langeland. But only twice did the AED arrive within 3-5 minutes of the initial call: one patient survived with a good result, and the other patient died of an intracranial haemorrhage. In the other five cases the AED arrived within 8-10 minutes of the initial call, one patient survived with severe brain damage and four patients died.

\section{Conclusion}

The Langeland AED project answers a call for shorter response times. The project hopes that the FirstAED GPS technology and the iPhone $4 \mathrm{~S}$ telephones to the rescuers will shorten the response times to below 5 minutes.

\section{Author details \\ ${ }^{1}$ Department af Cardiology, Odense University Hospital, Denmark. ${ }^{2}$ The Langeland AED project, Denmark.}

Published: 16 April 2012

doi:10.1186/1757-7241-19-S2-P47

Cite this article as: Henriksen et al:: The Langeland AED project - call for shorter response times (FirstAED). Scandinavian Journal of Trauma, Resuscitation and Emergency Medicine 2012 19(Suppl 2):P47.

*Correspondence: f.l.henriksen@dadlnet.dk

'Department af Cardiology, Odense University Hospital, Denmark

Full list of author information is available at the end of the article

(c) 2012 Henriksen et al; licensee BioMed Central Ltd. This is an Open Access article distributed under the terms of the Creative 